\title{
Alternative Optimal Social Orders
}

\section{JAN TINBERGEN*}

The structure of the optimal order should be found by scientific analysis. State of the art shifts over time. Marx's scientific socialism was based on science a century ago; it must be adapted accordingly.

Laissez faire was based on too simple assumptions. Collective goods and marginal welfare equality require State intervention. Level of decision-making must be supranational in some fields. Controversial points and the research needed to reduce controversies are listed.

\section{INTRODUCTION}

By the social order of a human society let us understand the set of institutions which are the framework in which human life is proceeding. Examples of institutions are governments at various levels, schools, and churches, but also markets. Each institution has a number of tasks and acts according to certain rules. These rules are set by the society's authorities, the rulers of the nation or other political entity (e.g. province, or group of nations united by a treaty). An optimal social order is one considered the best among various conceivable orders. One way or another, the optimal order is believed to maximize social welfare within the constraints set by nature, knowledge or creed. Examples of constraints are production functions; these may refer to the laws of nature which determine the growth of wheat or to the laws of technology which determine the quantity of iron to be obtained from iron ore, scrap and coal in a blast furnace.

In different historical periods or in different nations at the same time we observe differing social orders chosen as the best. Industrial countries around 1850 had an order close to "capitalism" or "laissez faire"; at present, countries under 
communist rule have an order close to "socialism" or a "centrally planned" economy. Many least-developed countries have an order called feudalism, and so on. There are also many mixed, sometimes "dual", orders.

The practical shaping of social orders is largely done by politicians. Description and analysis of social orders are the tasks of scientists; and various sciences deal with various aspects of the orders. Sociologists deal with group behaviour and relations between groups. Lawyers deal with the content of the rules set by the order's institutions. Political scientists observe and analyse the behaviour of politicians. Economists study the use of scarce resources for optimally satisfying human needs, and so on.

It is also possible for the methods in use in one science to be applied to the problems dealt with by another science. Such a procedure contributes to what we call interdisciplinary research and may lead to an enrichment of the sciences concerned.

In this article, the following four main subjects will be dealt with in four correspondingly numbered sections:

1. A discussion of the role a scientific treatment of the optimal social order may play in international understanding and, through it, in contributing to peace;

2. Sketch of an interdisciplinary treatment of the problem of the optimum social order, using the economic methods;

3. The major controversial points pertaining to this treatment; and

4. Some remarks on the empirical data needed to help decision-making in these controversies.

\section{ROLE OF SCIENTIFIC TREATMENT IN INTERNATIONAL UNDERSTANDING}

Scientific treatment of any problem is a "dated" activity. Science is in a permanent state of development and what was considered scientific in 1700 was not considered scientific any more in 1900 . Science passes through a succession of "states of the art" and the best we can do if we want to deal "scientifically" with some problem is to use the latest known "state of the art" of the sciences applied. Karl Marx claimed to have introduced "scientific socialism" in contradistinction to "utopian socialism" as described or analysed by some of his predecessors. The scientific treatment of a problem is seen to be at variance with an intuitive treatment or a treatment in the light of the interested persons or parties. As such, it is more convincing, closer to "the truth" and, hence, superior. When interpreting Marx, we must not forget that he wrote more than a century ago. He was unable to use the results of scientific research obtained after 1883 , or the events that took place after
1883. He could not know about nuclear energy and armament; neither could Lenin. Today's generation must do the scientific processing of these new developments all by itself, using today's state of the art.

One aspect characteristic of Marx's work remains important anyway: a scientific treatment of the problems faced by today's world, and in particular by today's superpowers, is superior to a treatment based on personal or group interests whether business interests or rulers' interests. If we advocate more freedom, in what ever sense, the strong will profit at the expense of the weak. If we derive our solutions of social problems from a philosophy favouring the weak, i.e. those who are suffering, there will be a change to the advantage of the weak. An Islamic order prohibiting interest on loans may be an example. An argument starting from personal or group advantages, however, will always be less convincing to the other party than a scientific argument. In that sense, a scientific treatment will be more helpful to building bridges. It presupposes a truly scientific attitude on both sides, that is a willingness to accept the evidence of empirical facts and true curiosity. Such attitudes are, moreover, in the interest of the discussants involved. They have a greater chance of persuading others.

\section{THE PROBLEM OF THE OPTIMUM ORDER, APPROACHED BY ECONOMIC METHODOLOGY}

As announced, we will make an attempt to sketch out an interdisciplinary treatment of the problem of the optimal social order. This implies our using parts of a variety of sciences: among them are psychology (since human preferences and human attitudes are involved), pedagogics (since schools will be among the institutions to be considered), biology (since food production comes in), physics and technology (since processing of minerals enters the picture), and so on. Our scientific procedure will be inspired to a large extent by economic methods, partly because economic aspects are important, but partly because an economist cannot help using economic methods, and, finally, because in some respects economics is ahead of other social sciences.

As in many sciences, we will base our sketch on a process of diminishing abstraction. This is not a necessity, but has some expository advantages. Politicians and economists have historically passed through various phases parallel to our process.

If only individual goods exist, or are preferred by members of the society, and if these can only be produced by processes showing diminishing returns, it can be shown that a maximum of social welfare, defined as the sum total of individual satisfactions, will be attained by a system of markets where free competition prevails. Such markets should exist for all goods and for all production factors. Production processes include the production of human capital, that is various skills, for which 
also markets exist, and incomes may be seen as the sum total of the prices of the quantities of skills offered on the labour market : cf. [3]. The social order typically would be a laissez-faire order, without a government even.

A next step in our procedure of diminishing abstraction consists of the introduction of collective goods. Neglecting details, we consider, to begin with, their main characteristic that consumption of some quantity of a collective good by person 1 does not reduce at all its consumption possibility for other persons, 2, 3, etc. Wellknown examples are TV broadcasts and similar forms of information, and cleaning of the environment, and (although in a slightly more restricted form) the police. Collective goods cannot be exchanged on a market and the decision about how much of each shall be produced must be taken collectively (i.e. by parliament). So, here new institutions are needed; in the simplest case, a parliament and its executive, the government.

Further refinements may consist of the introducton of non-transportable goods: buildings and location-bound services (retail trade, local transportation, elementary schools). They give rise to semi-collective goods [2] and to lower-level governments as additional institutions.

A major problem about collective goods is: Which portion of the total production should be devoted to them? In concrete political language, this is a part of the problem of the size of the public sector. A part of this problem is the propensity to evade taxes which sets a limit, or at least creates a trade-off, with regard to that size.

In order to maximize social welfare, conceived as the sum total of individual welfares (or satisfactions), marginal welfare from income has to be equalized among individuals. This requires an institution of income redistribution, such as taxes, subsidies and social security.

Technology will not always make available diminishing returns to scale. Increasing returns to scale may impose the necessity of two-part pricing (as applied by public utilities and transportation). The international and interregional division of labour in an optimal world order will be determined to a large extent by the capitalintensity of transportable (and hence tradable) goods and services: cf. [7] .

A last aspect in this sketch is the phenomenon of external effects of human decisions. A modern example is environmental damage, which may affect the welfare of people not involved in decision-making. For a maximization of social welfare, decision-making should be extended to include all the affected persons (usually by representation). Thus, environmental protection activities should be determined at a governmental level high enough to keep external effects negligible.

A major innovation of political science is needed with regard to military conflicts. Much more weight should be given to the economic aspect of war. Since the economic effect of war has become increasingly negative and far more negative than, for instance, erroneous socio-economic policies, anti-militarist activities have become much more productive than is usually assumed. The framework of this sketch does not allow further elaboration, but this item on the agenda of future and urgent - research should at least be mentioned.

\section{CONTROVERSIAL POINTS IN THE PRECEDING SKETCH}

As stated earlier, a large number of controversial views exist on the theory of the optimal order. A selection will suffice to show the extent and degree of disagreement.

The definition of social welfare as the sum total of the individual welfares of all citizens may be the first to be selected. For the addition of individual welfares of all citizens, this welfare must be measurable. Many economists and psychologists doubt or deny this measurability. Those who deny measurability in effect maintain the impossibility of equalizing marginal utility and so have to find another basis for income redistribution with the aid of taxes, subsidies and social security systems.

This also implies that they have to find another basis for a decision on the size of the public sector. In communist-ruled countries it is believed that there should be a very large public sector and that markets should be replaced, to a considerable extent, by central planning. In other countries, preference is given to a small public sector, because public enterprises and services are said to be less productive than private enterprises. The advocates of markets and private enterprises point to the negative effect of bureaucracy on the overall productivity of the economy. Those in favour of a system of progressive taxes point to the inequity of the income distribution in the absence of such taxes, whereas those against such taxes fear a reduction of savings which would reduce the rate of growth of the economy. This argument is countered by the proponents of high and progressive taxes who point to the possibility of capital formation by the State.

Increasing returns to scale will automatically lead to large enterprises, which implies high productivity. They may also lead to monopolies and these are suboptimal. Two-part pricing constitutes a possibility of maintaining competition, however.

Large differences of opinion prevail on the optimal international division of labour. The suggestion that labour-intensive industries be located in less developed countries and capital-intensive industries in developed countries is often opposed by less developed countries because in labour-intensive industries incomes per employee are lower than in capital-intensive activities. This argument overlooks the facts that labour-intensive industries create more employment per unit of capital than the capital-intensive ones and that developing countries suffer from a high scarcity of capital. 
A number of economists point to other characteristics of industries which should be taken into account, sometimes called the product cycle theory: technologies to produce a given good pass through a cycle running from simple to more sophisticated ones and finishing with standardized automation.

Another way of characterizing these various phases of technology is to consider the complexity of the product [1]. The two theories are less different if one takes into account human capital as a form of capital. The more complex products require special skills, which constitute human capital, and this, too, is scarce in less developed countries.

\section{EMPIRICAL DATA NEEDED TO REDUCE CONTROVERSIES}

Opinion differences among economists as well as those among politicians can be reduced if more concrete numerical data are available. Questions of productivity differences between public and private activities require measurement of their productivities. Similarly, differences in capital intensity between alternative technologies, too, can be cnecked by empirical research. Whereas a considerable quantity of this type of information is available already, it is lacking in other cases and in particular for the newest industries around electronics and their application. Programmes of technological research can be formulated relatively easily since the concepts involved are clear.

Less easy are the programmes on a number of psychological data. Beginning with the simpler issues again, the preferences for individual as distinct from collective goods can be measured from well-formulated questionnaires asking whether an expenditure of Rs. 1000 on ice cream or coca-cola would or would not be preferred to the expenditure of an equal amount on schooling facilities, a bridge or a highway (to be specified as to location, quality and so on).

The most difficult part of empirical research concerns the possibility of measuring individual welfare. On this issue, an expanding scientific literature is available, inspired by a series of measurements carried out by Professor B. M. S. Van Praag and collaborators of the University of Leiden, The Netherlands [4]. A slightly different approach has been followed by this author $[5 ; 6]$. It is in this area that a vast research programme should be designed to obtain better data on a number of capabilities characterizing a sample of the active population of some country and the capabilities required to satisfactorily perform in the job they hold. For one capability (years of schooling completed) we now have data; for other capabilities only very limited information is accessible to scholars working in this field, but presumably personnel departments of large enterprises have such material: Some public opinion polls, too, have contributed information. Here we are close to the frontier of the sciences involved.

\section{REFERENCES}

1. Boon, G. K. "Theory and Reality in North-South Trade: Some Explanations", De Economist. 131. 1983. pp. 256-272.

2. Dreze, J. "Investment under Private Ownership". Chapter 9 in J. Dreze (ed.) Allocation under Uncertainty, Equilibrium and Optimality. McMillan. 1974.

3. Hartog, J. Personal Income Distribution. A Multicapability Theory. Boston/ The Hague/London: Martinus Nijhoff. 1981.

4. van Praag, B. M. S. "Reflections on the Theory of Individual Welfare Functions". Leiden: Center for Research in Public Economics, University of Leiden. 1981. (Report 81.14)

5. Tinbergen, J. "Allocation of Workers over Jobs". De Economist. 132. Forthcoming, 1984.

6. Tinbergen, J. Income Distribution, Analysis and Policies. Amsterdam: NorthHolland. 1975.

7. Tinbergen, J. "Maximizing National Product by the Choice of Industries" Pakistan Development Review. Vol. XXI, No. 2. Summer 1982. pp. 93-103. 